\title{
Visuo-auditory interactions in the primary visual cortex of the behaving monkey: Electrophysiological evidence Ye Wang ${ }^{1,2}$, Simona Celebrini ${ }^{1}$, Yves Trotter ${ }^{1}$ and Pascal Barone*1
}

\author{
Address: ${ }^{1}$ Centre de Recherche Cerveau \& Cognition, UMR CNRS 5549, Faculté de Médecine de Rangueil, 31062 Toulouse Cedex 9 , France and \\ 2Department of Neurobiology and Anatomy, University of Texas-Houston Medical School. Houston TX, USA \\ Email: Ye Wang - ye.wang@uth.tmc.edu; Simona Celebrini - simona.celebrini@cerco.ups-tlse.fr; Yves Trotter - yves.trotter@cerco.ups-tlse.fr; \\ Pascal Barone* - pascal.barone@cerco.ups-tlse.fr \\ * Corresponding author
}

Published: 12 August 2008

BMC Neuroscience 2008, 9:79 doi:10.1 |86/147|-2202-9-79
Received: 10 January 2008

Accepted: 12 August 2008

This article is available from: http://www.biomedcentral.com/I47/-2202/9/79

(C) 2008 Wang et al; licensee BioMed Central Ltd.

This is an Open Access article distributed under the terms of the Creative Commons Attribution License (http://creativecommons.org/licenses/by/2.0), which permits unrestricted use, distribution, and reproduction in any medium, provided the original work is properly cited.

\begin{abstract}
Background: Visual, tactile and auditory information is processed from the periphery to the cortical level through separate channels that target primary sensory cortices, from which it is further distributed to functionally specialized areas. Multisensory integration is classically assigned to higher hierarchical cortical areas, but there is growing electrophysiological evidence in man and monkey of multimodal interactions in areas thought to be unimodal, interactions that can occur at very short latencies. Such fast timing of multisensory interactions rules out the possibility of an origin in the polymodal areas mediated through back projections, but is rather in favor of heteromodal connections such as the direct projections observed in the monkey, from auditory areas (including the primary auditory cortex $\mathrm{Al}$ ) directly to the primary visual cortex $\mathrm{VI}$. Based on the existence of such $\mathrm{Al}$ to $\mathrm{VI}$ projections, we looked for modulation of neuronal visual responses in VI by an auditory stimulus in the awake behaving monkey.

Results: Behavioral or electrophysiological data were obtained from two behaving monkeys. One monkey was trained to maintain a passive central fixation while a peripheral visual $(V)$ or visuoauditory (AV) stimulus was presented. From a population of $45 \mathrm{VI}$ neurons, there was no difference in the mean latencies or strength of visual responses when comparing $V$ and $A V$ conditions. In a second active task, the monkey was required to orient his gaze toward the visual or visuo-auditory stimulus. From a population of 49 cells recorded during this saccadic task, we observed a significant reduction in response latencies in the visuo-auditory condition compared to the visual condition (mean 61.0 vs. $64.5 \mathrm{~ms}$ ) only when the visual stimulus was at midlevel contrast. No effect was observed at high contrast.

Conclusion: Our data show that single neurons from a primary sensory cortex such as $\mathrm{VI}$ can integrate sensory information of a different modality, a result that argues against a strict hierarchical model of multisensory integration. Multisensory interaction in $\mathrm{VI}$ is, in our experiment, expressed by a significant reduction in visual response latencies specifically in suboptimal conditions and depending on the task demand. This suggests that neuronal mechanisms of multisensory integration are specific and adapted to the perceptual features of behavior.
\end{abstract}




\section{Background}

The classical view of multisensory integration, based on anatomical grounds [1], proposes that each sensory modality is processed through separate channels from the sensory receptors to the primary sensory areas and then further integrated into associative unimodal areas converging at the level of cognitive polymodal areas [2]. Indeed, in primates, neuronal responses to more than one sensory modality have been described in areas higher-up in the hierarchy like the frontal, temporal and parietal lobes [3-9]. While these polysensory areas are the best candidates to support sensory fusion, recent studies in humans have surprisingly revealed that multisensory interactions can take place in early stages of sensory processing, in regions thought to be involved in only one modality $[10,11]$. This result has led to a reappraisal of the cortical regions involved in multisensory integration [12]. In humans for example, imaging [13-16] and EEG studies $[17,18]$ have clearly shown heteromodal responses in sensory areas even at the level of the primary sensory fields. Furthermore, the discovery of heteromodal connections directly linking areas involved in different sensory modalities could be the anatomical support of such interactions [19-21]. For example, in the monkey, the core of the auditory cortex receives direct inputs from both somatosensory and visual areas [19]. It can be inferred that these cortical heteromodal connections, as well as the thalamocortical loop $[22,23]$, could be the anatomical pathway responsible for the visual [24-26], somatosensory [27,28] or proprioceptive [29] influences observed in the monkey auditory cortex [30].

In the normal adult cat, some early electrophysiological studies have reported auditory responses in visual areas [31-33], a result which is still controversial [34]. Multisensory integration in the primary visual cortex (V1) of the monkey has not been established, apart from a clear influence of a non visual eye position signal on visual activity $[35,36]$. However, auditory or visuo-auditory responses in area $\mathrm{V} 1$ are highly probable since we have demonstrated direct projections from the auditory cortex (including A1) and the polymodal area STP to area V1 in the calcarine sulcus [21]. Furthermore, the auditory system is activated more precociously that the visual one, and for example the latencies of auditory responses recorded in areas AI and STP are about 35 and $45 \mathrm{~ms}$ respectively [37,38]. Consequently it conceivable that an auditory stimulus can modulate the visual responses in V1 where the mean onset latencies are longer, between $50-70 \mathrm{~ms}[39,40]$. As some authors have reported even shorter latencies in V1 when using high contrast stimuli [41], one could expect that an auditory stimulus would affect mostly late visual responses such as the one obtained using non-optimal stimuli (ie. low visual contrast).
We thus conducted an electrophysiological study to look for visuo-auditory interactions at the single cell level in primary visual cortex. Because the auditory projections to V1 are more dense at the representation of the peripheral visual field, a region of space that encompasses most of the auditory receptive field in AI $[42,43]$, our electrophysiological recordings targetted visual cells with RF located between 10 and $20^{\circ}$ of retinal eccentricity.

\section{Methods}

The present study is based on data obtained from two monkeys (Macaca mulatta) trained to performed a visual or visuo-auditory oculomotor task. A detailed description of the general methods used in the electrophysiological recording has been reported in a previous study [44]. All experimental protocols, including care, surgery, and training of animals, were performed according to the Public Health Service policy on the use of laboratory animals and complied with guidelines of the European Ethics Committee on Use and Care of Animals.

\section{Behavioral task}

The core of the present study concerns two monkeys (Mk1 and $M k 2$ ) trained to perform a visually guided saccadic task during which the visual target could be accompanied by an auditory stimulus (V/VA active task). A trial was initiated by the appearance of a fixation point (FP) located at the center of the video screen and of a size of 0.2 degree. The monkey had to direct its gaze and to maintain fixation at this central point. The duration of presentation of the FP was randomized between trials and lasted between 1500 to $1800 \mathrm{~ms}$. Simultaneously, with the extinction of the FP, a peripheral visual target was flashed for $50 \mathrm{~ms}$. The monkey was required to perform a saccade in the direction to the locus of the visual target within $250 \mathrm{~ms}$ of its appearance. Responses were considered as correct when the saccades were performed within a window of 4 $\times 4$ degrees centered on the visual target, and in these cases a few drops of fruit juice were delivered to the monkeys as a reward. In half of the trials, presented randomly, a $25 \mathrm{~ms}$ sound (a white noise) was delivered from a speaker located at the same eccentricity on the azimuth as the visual stimulus. In such visuo-auditory trials (VA), the visual and the auditory stimuli were presented at the exactly same time. In both conditions (V and VA) the monkey was required to perform a saccade directed toward the visual target and consequently, the auditory stimulus had no behavioral meaning for the animal. Note that we did not train the monkeys to perform a saccade toward the auditory stimulus alone.

The first monkey engaged in the present study (Mk1) was first trained to perform two control tasks before the $V / V A$ active task. In a first stage, the monkey was trained to perform a simple passive fixation task (V/VA passive task). Fol- 
lowing the presentation of the FP (of variable duration from 1500 to $1800 \mathrm{~ms}$ ), a visual or visuo-auditory stimulus was presented for $500 \mathrm{~ms}$ together with the FP. To get rewarded, the monkey had to maintain its fixation until the FP was extinguished.

Further, Mk1 was trained in a visual control task (V-only control task), during which the color of the FP informed the animal whether he had to maintain a central fixation (blue FP) or to make a saccade toward a visual peripheral stimulus (Red FP). In this case the visual stimulus was never accompanied by an auditory stimulus. The timing of stimulus presentation was identical to that described for the active task (50 ms).

The monkey Mk1 was engaged successively in each of these different protocols for several months, a period during which electrophysiological recordings were performed in the primary visual cortex (see below). Mk2 was trained from the beginning to do the VA active task.

\section{Apparatus and electrophysiological recording}

The visual stimuli, delivered by a Vision Research Graphics system with a refresh rate of $120 \mathrm{~Hz}$, were presented in total darkness on a video screen located $50 \mathrm{~cm}$ in front of the monkey. The FP consisted of a single dot of $0.2^{\circ}$ of size. Peripheral visual stimuli consisted of dynamic random dots (dRD, density $20 \%$, and dot size 3.5 min of arc) presented at either side of the central FP in a random order. Two or three contrast levels of the dRD were used, from low (15\%) to medium (55\%) or high values (88\%). During the behavioral sessions, the visual stimuli were $5^{\circ}$ of size and presented at 10 or $20^{\circ}$ of retinal eccentricity in azimuth, and -5 or $-10^{\circ}$ in elevation. During the electrophysiological recording sessions, the size and the location of the dRD were adjusted to the size and location of the cell receptive fields. Auditory stimuli (white noise, $72 \mathrm{~dB}$ SPL) were presented through a multi-channel sound card to one of 6 speakers located just below the video screen (at about 3 degrees below the lower border of the monitor). The horizontal position of the speakers was adjustable to be spatially adjusted in the horizontal plan just below the visual $\mathrm{dRD}$. Thus the auditory stimuli are matching the horizontal location of the cell receptive fields, but not the vertical one (see figure 1). Further, to minimize the reflection of the sound, the animal was placed in a restricted space ( 1 by 1 meter for each sides) covered of thick black curtains. Acoustical reflection could be problematic for sound localization. However in our protocol the sound had no meaning to perform correctly the oculomotor task of the monkey and we believe that any sound reflection did not affect the monkey performance. Further, based on previous electrophysiological data obtained in the auditory pathway [45], in situation of reverberent environment, a cell's response to the leading source is always
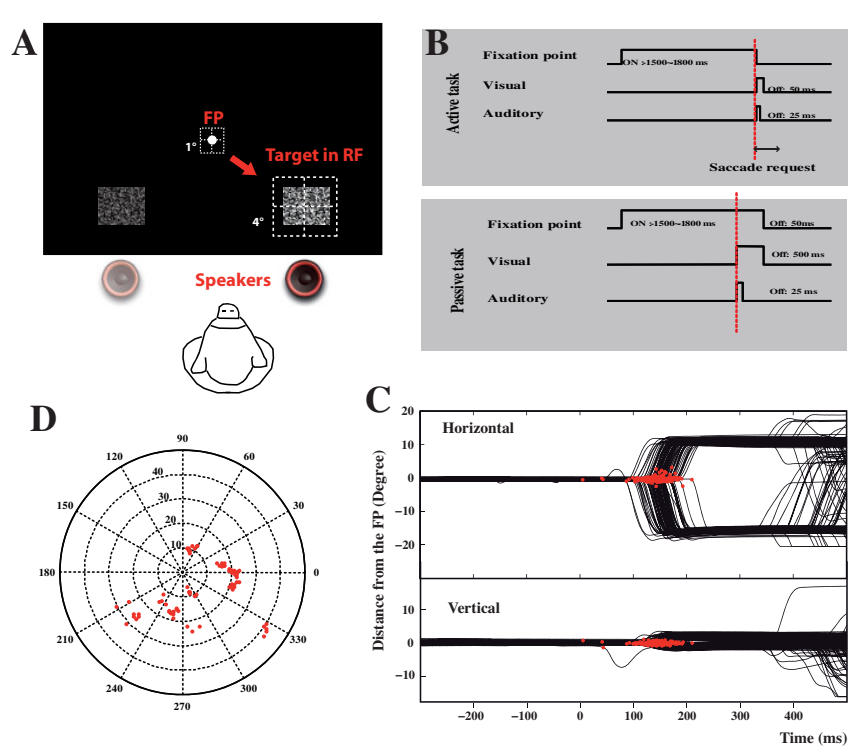

\section{Figure I}

Experimental protocol.A. In the active Visuo-Auditory task, the monkey had to perform a saccade toward a visual cue located on the right or left side of the central fixation point. The visual stimulus was placed inside the neurons RF or at the opposite location. Auditory speakers were placed just below the visual location. Dashed squares represent the control windows regulating the eye movement for both the fixation and the saccadic periods. B. Temporal succession of the visual and auditory events in the active (upper panel) or passive (lower) tasks. C. EEG recordings of a monkey (Mkl) during a saccadic task oriented toward a visual cue located at 16 degrees on the left or right site of the fixation point. The upper and lower panels correspond to the horizontal or vertical eye movements respectively. Red dots represent the saccade latencies as described in the method section. Note that the anticipatory saccades obtained at latencies lower that $30 \mathrm{~ms}$ were not included into the analysis. D. Polar plot showing the receptive fields location of the recorded single cells. Most of the cells have RFs located at retinal eccentricities beyond $10^{\circ}$.

stronger than that observed to the lagging one, especially at short lag/lead delays [46]. In consequence, in absence of a sound-attenuated chamber, we think that in our experimental set-up the main auditory effect observed on V1 cells will be produced by the leading direct sound source located in front of the animal.

Protocols control and data acquisition were executed under REX system. To avoid a jittering when generating the auditory stimulus through Windows system, all stimuli were pre-generated and stored in memory. Then we added a buffer silent time before each auditory stimulus. Triggers corresponding to the beginning of auditory stimuli (from the buffer) and the first visual frame (through 
VRG) were sent to REX system. The audio buffer length was adjusted to synchronize the visual and auditory stimuli at expected delay.

Aseptic surgery was performed to attach a head-post to the skull and to implant a scleral search coil in both eyes. Single-unit recordings were made in one of the two monkeys (Mk1). Once the monkey had reached a high level of performance, a second surgery was performed to implant a recording chamber above the peripheral visual field representation in V1 located in the calcarine sulcus [47]. The skull was removed within the chamber, and a fixed grid was placed, so that the electrode penetrations were spaced $1 \mathrm{~mm}$ apart. Guide tubes were used to help to penetrate the dura. Sterile, tungsten-in-glass electrodes of $\sim 1 \mathrm{M} \Omega$ impedance were inserted with a hydraulic microdrive fixed to the recording chamber, perpendicular to the cortical surface. Extracellular recordings were carried out in both hemispheres of the monkey from which the visual responses were previously analyzed for disparity selectivity (see [48]). Action potential waveforms were sorted online with the help of a spike sorting software (AlphaOmega $\mathrm{MSD}^{\circledR}$ ) and only single units recorded through complete trials were selected for analysis.

\section{Data analysis}

The behavioral analysis was derived from the performance of the two monkeys trained to perform the visually and visuo-auditory guided saccadic task (V/VA active task). For each trial we determined the saccade latency defined as the first point when the eye position was significantly different from the average eye position signal during the 300 ms prior to stimulus offset. This corresponded to the time at which the difference between the current position and the mean was 2 times greater than the maximum range observed during the fixation period. Then we performed a statistical analysis (Multifactor Anova) to compare the saccade latencies obtained during the $\mathrm{V}$ and VA conditions. We used a multi-way ANOVA test to the saccade latency obtained in each monkey. Contrast ( 3 groups in MK1, 2 groups in MK2), eccentricity (2 groups), and V or VA stimulation ( 2 groups) were treated as different factors. We checked both single factor and two-factors interactions. In case of p value too low to be computed, as we know it show very high significance, we also indicate $\mathrm{F}$ value as references. Post-hoc test was then applied to compare the saccade latencies between individual pair of conditions.

For each neuron in each condition, the neuronal activity was recorded for 20-40 correct trials. Two parameters were studied to analyze the effect of visuo-auditory interactions in V1 cells : the amplitude and the latency of the visual responses. To measure the visual response latency, we first computed histograms of neuronal activity aligned on the stimulus onset. As previously described [48,49], we further smoothed the accumulative line by simulating each spike as a mini gauss function (Amp. = 1; Sigma $=4)$. So within each $1 \mathrm{~ms}$ bin, we got statistical spike numbers of 40 (trial number)*10(gauss summation) ms window. Then we measured the baseline average spike number per bin in the $200 \mathrm{~ms}$ prior to stimulus onset, and used it as the Poisson distribution lambda parameter of spontaneous activity. So the threshold of response activity was the smallest number $n$ that the Poisson cumulative density function evaluated which equaled or exceeded 0.99. Thus, if the firing property obeyed the same Poisson distribution as the baseline, the spike number within each bin would not exceed this value at $99 \%$ confidence. We calculated this number $n$ by using the Matlab Poisson function. We then used a detection window of $4 \mathrm{~ms}$ and measured activity starting from visual stimulus onset. If the minimum value inside this window was greater than $n$, we determined the response latency as the first point of the window. Because we could only get one latency value for a group of trials, we used bootstrap methods to compare the activity between conditions : shuffle latencies were calculated from the same number of trials in a sample taken randomly from both conditions. This was performed 4000 times to obtain 2000 randomly grouped pairs, from which we calculated the individual difference within pairs. The bootstrap $\mathrm{p}$ value is the ratio of pairs for which differences were no less than the values obtained from the experimental data. At the population level, after normalization of the responses, we used an Anova test to analyze the factor effect on response amplitude or latency, and paired t-tests for post hoc comparison.

\section{Results \\ Visuo-auditory interaction: behavioral evidence}

In a first stage we analyzed the effect of visual conditions on the saccadic reaction times (sRT) performed by the two monkeys (Fig 2). The present data concern behavioral latencies obtained in highly trained monkeys and are based on several thousands of trials. Across the different conditions of stimulation (uni- or bimodal, at different contrasts or eccentricities), sRT values were on average $155,0 \mathrm{~ms}$ for Mk1 and 167,6 ms for Mk2 which correspond to the range of values reported in other studies using similar experimental conditions)[50]. First in uniand bimodal conditions we observed a decrease in sRT in both monkeys when the contrast of the visual cue increased (Anova, Mk1, F = 4012, $\mathrm{p}=0 ; \mathrm{Mk} 2, \mathrm{~F}=20.39$, p $=1.64 \mathrm{E}-9)$. This was particularly evident for Mk1 during a $20^{\circ}$ task in visual-only conditions, with sRT of $172 \mathrm{~ms}$ when the contrast was low and of only $144 \mathrm{~ms}$ at high contrast. This is in agreement with numerous similar psychophysical studies on RT in both man and monkey [5153]. Furthermore, in both sensory conditions, the monkeys had much shorter sRT when the saccades were 

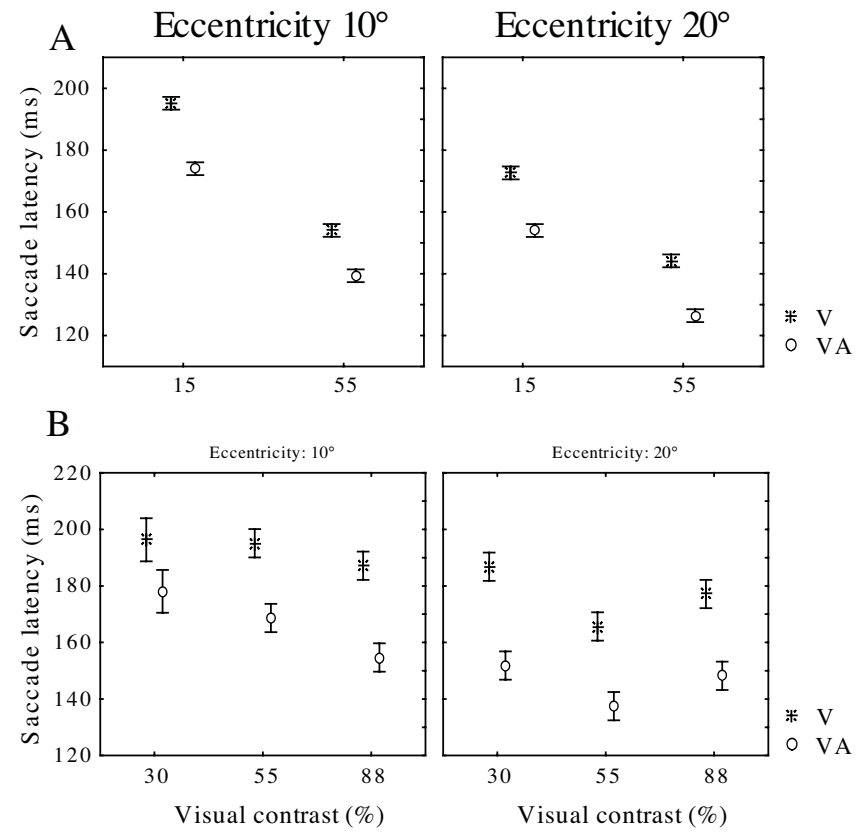

Figure 2

米

Saccadic reaction times ( \pm sd) of the individual monkeys (A: monkey I; B: Monkey 2 ) according to the eccentricity of the visual target ( $10^{\circ}$ left panels; $20^{\circ}$ right panels) presented at different contrasts and during the visual-only (*) or visuo-auditory conditions $(\bigcirc)$. Saccadic latencies are shortened both when increasing the visual contrast and when the visual cue is presented simultaneously with the auditory stimulus (VA conditions).

directed toward the more eccentric $\left(20^{\circ}\right)$ peripheral target (Mk1, F = 527.65, Mk2, F = 148.17, $\mathrm{p}=0$ both cases $)$. On average, independent of the visual contrast, saccade latencies toward eccentric cues located at $20^{\circ}$ were $10 \%$ shorter than those toward a cue at $10^{\circ}$. This difference in latencies tended to be larger in the visuo-auditory $(12.6 \%$ shorter at $\left.20^{\circ}\right)$ compared to the visual-only condition $(8.6 \%)$. Again, this effect of the eccentricity of a target on the saccadic reaction time is similar to that observed in humans [54].

We analyzed next the effect of bimodal stimulation by comparing the sRT in the V-only and VA conditions (Fig 2). As classically reported and resulting from multisensory integration [55], we observed a strong reduction in the saccade latencies in the VA condition compared to the Vonly situation. This reduction was observed at all eccentricities (Anova, $10^{\circ}: \mathrm{Mk} 1 \mathrm{~F}=231.17$, , Mk2 $\mathrm{F}=66.67$, both $\mathrm{p}=0 ; 20^{\circ} \mathrm{Mk} 1 \mathrm{~F}=404.76, \mathrm{Mk} 2 \mathrm{~F}=271.45$, both $\mathrm{p}$ $=0$ ) and at all contrasts of the visual target (Anova, Mk1, $15 \% \mathrm{~F}=516,55 \% \mathrm{~F}=329.7$, both $\mathrm{p}=0$; Mk2 30\% F = 107.3, $\mathrm{p}=0,55 \% \mathrm{~F}=69.38, \mathrm{p}=3.33 \mathrm{E}-16,88 \% \mathrm{~F}=$ $117.45, \mathrm{p}=0)$. On average, when combining all condi- tions, the decrease in sRT ranged from 10\% (Mk1) to $15 \%$ (Mk2) when saccades were made toward the VA stimulus. The rule of inverse effectiveness [55], proposes that the higher benefits resulting from multisensory integration should be obtained in sensory conditions of low saliency. Thus we searched for an effect of visual contrast on the reduction of sRT during visuo-auditory saccades. In Mk2, for which data were obtained at 3 different contrasts (3055 and $88 \%$ ), there was a tendency toward a more pronounced shortening of sRT at low contrast. When saccades were made at $20^{\circ}$, sRT in VA conditions were $19 \%$ shorter at a low contrast ( $187 \mathrm{~ms}$ in V-only vs. $152 \mathrm{~ms}$ in VA, $\mathrm{p}=$ $6.38 \mathrm{E}-21)$ while the decrease was only $14 \%$ at high contrast (174 ms vs. $150 \mathrm{~ms}, \mathrm{p}=7.29 \mathrm{E}-23$ ). However we did not replicate these results in the second monkey or in all conditions. In $\mathrm{Mk} 1$, at $20^{\circ}$, the reduction was similar at low $(11.1 \%$ decrease) and high contrast $(11.9 \%$ decrease). Thus, we observed a constant decrease in sRT at all the visual contrasts used, data which seem to contradict the rule of inverse effectiveness. However, this could be due to the level of training. When analyzing the data during the first sessions of the behavioral training of $\mathrm{Mk} 1$ (not shown), we found a stronger decrease in sRT at low contrast, but at that time the monkey was not performing at an efficient level and his saccade latencies were much longer. This effect disappeared after extensive training over several weeks.

Visuo-auditory interaction: electrophysiological evidence The present study is based on three sets of visual responsive single units (total $\mathrm{n}=136$ ) recorded in the primary visual area $\mathrm{V} 1$ of one monkey (Mk1). Each set of cells was obtained during a single behavioral condition (V/VA active task $n=49 ; V / V A$ passive task $n=45 ; V$-only control task $n=42)$, all cells were recorded in peripheral V1 and most of them (69\%) were located in the upper bank of the Calcarine sulcus (Fig 1) and present a receptive field located over $10^{\circ}$ of eccentricity in the lower visual field. The size of the receptive fields were ranging between 1 and $4^{\circ}$ (see [48]) characteristic of those cells recorded in the peripheral representation of $\mathrm{V} 1$.

\section{Auditory modulation of visual responses in V/VA active task}

The visual responses (discharge rate and latency) of 49 isolated V1 neurons were analyzed during the active visual and visuo-auditory tasks (Table 1 ). In the V-only conditions, the cells showed a strong phasic activity in response to the $\mathrm{dRD}$ and both the magnitude (Anova, $\mathrm{F}=4.5, \mathrm{p}=$ 0.0135 ) and latencies (Anova, $F=58.36, p<0.0001$ ) of the responses were affected by the contrast level as classically reported for V1 cells [56]. When comparing the response rates, we observed that while the discharge rates were similar at high (88\%) and medium (55\%) contrasts $(54.5 \mathrm{spk} / \mathrm{s}$ and $52.2 \mathrm{spk} /=\mathrm{s}$ respectively, paired t-test $\mathrm{p}=$ 0.18 , ns), the neuronal activity was, on average, much 
Table I: Response rates and latency values ( \pm se) of $\mathrm{VI}$ single units recorded during the V/VA active tasks using three different contrast levels.

\begin{tabular}{lcccc}
\hline & \multicolumn{2}{c}{ Response Rate $(\mathrm{spk} / \mathrm{s})$} & \multicolumn{2}{c}{ Latency $(\mathrm{ms})$} \\
\cline { 2 - 5 } & V-only & AV & V-only & AV \\
\hline Low level $(n=17)$ & $33.9 \pm 5.0$ & $35.7 \pm 5.1$ & $100.7 \pm 6.2$ & $96.8 \pm 6.2$ \\
Mid-level $(n=39)$ & $52.2 \pm 4.0$ & $52.7 \pm 4.1$ & $64.5 \pm 2.5$ & $61.0 \pm 2.3$ \\
High level $(n=45)$ & $54.4 \pm 3.9$ & $54.1 \pm 3.8$ & $49.2 \pm 1.8$ & $49.0 \pm 2.0$
\end{tabular}

lower at the low contrast of $15 \%$ (33.9 spk/s, paired t-test, $\mathrm{p}<0.001$, both comparisons). The cell latencies were also sensitive to the contrast level and we observed a progressive increase in the mean latency (table 1, paired t-test $\mathrm{p}<$ 0.001 for all comparisons) when presenting stimuli from

A

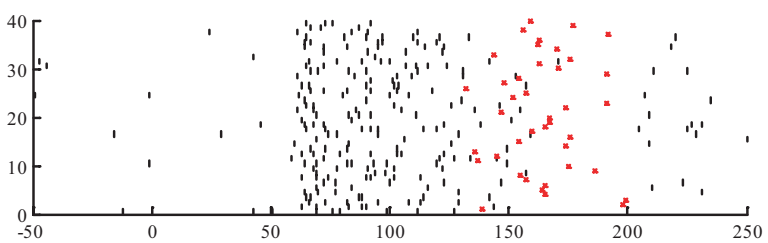

B

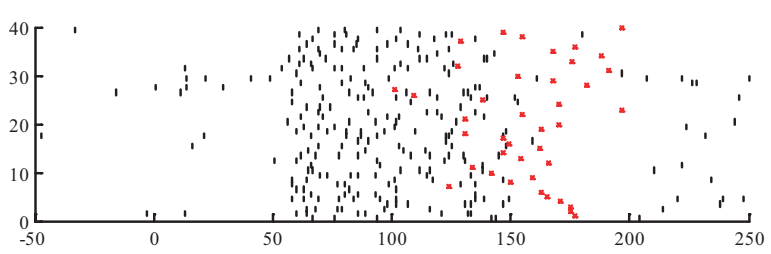

$\mathrm{C}$

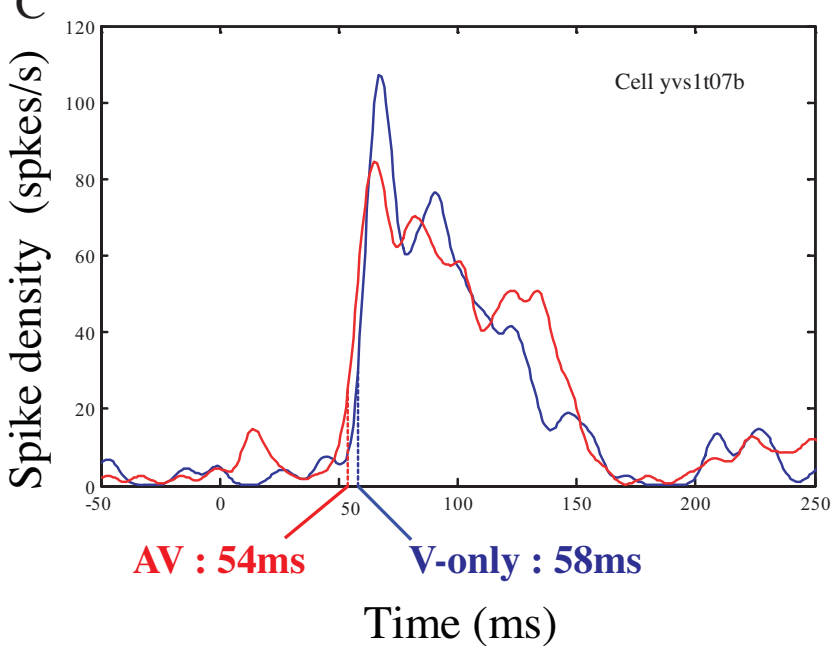

the high (49.2 ms), medium (64.5 ms) or low contrasts (100.7 ms). In the bimodal condition (VA active task), we observed exactly the same influence of visual contrast on the neuronal responses as expressed by an increase of discharge rate (Anova, $\mathrm{F}=3.65 \mathrm{p}=0.0296$ ) and a decrease of latencies when increasing the contrast levels (Anova, $\mathrm{F}=$ $52.31 \mathrm{p}=3.33 \mathrm{E}-16$, Table 1 ). Thus the simultaneous presentation of an auditory stimulus has no effect on the contrast dependent relationships of the visual responses of $\mathrm{V} 1$ neurons.

When we compared the $\mathrm{V}$ and $\mathrm{AV}$ conditions at constant contrasts, the simultaneous presentation of a spatially congruent auditory stimulus affects the cells activity by a change in the response latency. This is illustrated in two examples in figure 3. Both cells showed a characteristic

D

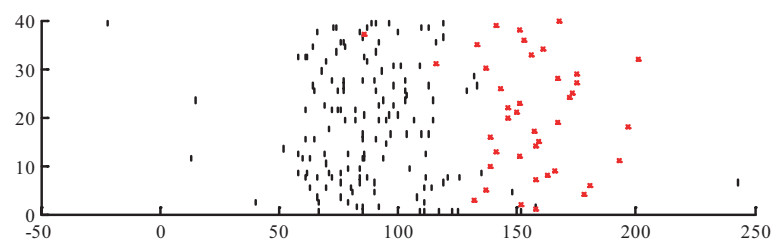

$\mathrm{E}$

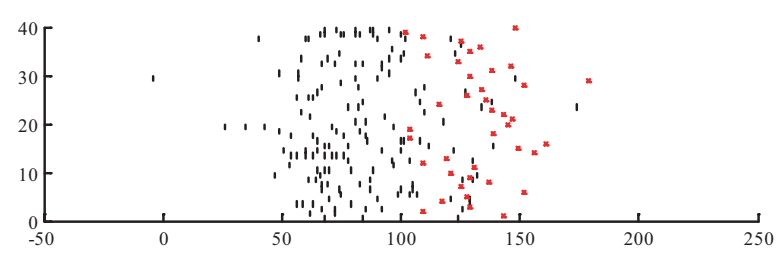

$\mathrm{F}$

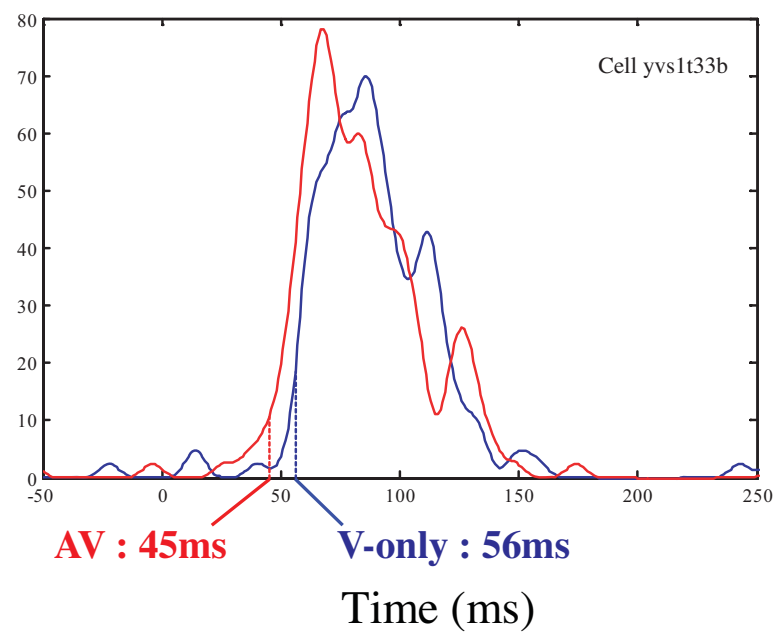

Figure 3

Examples of activity of two $\mathrm{VI}$ single cells that present a significant reduction of their visual responses latency during the bimodal visuo-auditory conditions (AV). A and D represent rasters of the cells activity in the visual-only condition, while $B$ and $E$ show the activity of the same cells in the visuo-auditory conditions. The red dots indicate the time at which the monkey is making a saccade toward the visual target. $\mathrm{C}$ and $\mathrm{F}$ represent the response peristimulus time histogram to visual (blue) or visuo-auditory (red) stimuli. In both cells, the AV response latency is shorter compared to the $\mathrm{V}$-only condition. 
phasic response to a dRD presented in their RF. While the frequency discharge was similar during the $\mathrm{V}$-only and $\mathrm{AV}$ conditions (paired t-tests, both cells, p > 0.05), the two neurons showed a significant decrease in latency. For example, cell \#33 (left panel) when stimulated at a midlevel contrast, had a mean latency of $56 \mathrm{~ms}$ during the visual task, a value that was reduced to $45 \mathrm{~ms}$ in the visuoauditory conditions (bootstrap, $\mathrm{p}=0.0415)$, while the spike discharge remained constant (35 and $38 \mathrm{spk} / \mathrm{s}$ respectively, paired t-tests, $\mathrm{p}=0.4874, \mathrm{~ns})$. This general effect of the auditory stimulus on the visual responses held when the analysis was performed at the population level. First when comparing the V-only and VA conditions, we did not see any significant change in the response rate of the cells at high and midlevel contrasts (Table 2, paired t-test $\mathrm{p}>0.5 \mathrm{~ns}$ for both conditions). However, at low contrasts we observed a slight increase in the response rate from $33.9 \mathrm{spk} / \mathrm{s}$ to $35.7 \mathrm{spk} / \mathrm{s}$ a difference that is just below the significance level (paired t-test, $\mathrm{p}=0.04$ ). The middle panel in fig 4 shows the distribution of the relative differences of response rates (in \%) between the uni- and bimodal conditions of all cells at each visual contrast. In the two higher contrast conditions, the distribution is centered at 0 , corresponding to an absence of variation of the neuronal discharge between the $\mathrm{V}$ and $\mathrm{AV}$ presentations.
However, the cell response latency was globally reduced when the auditory stimulus was delivered simultaneously with the visual target (Table 1). At the population level and at each contrast, the cells latency tended to be shorter. This is illustrated in Fig 4 by a leftward shift toward negative values in the distribution of the relative differences (in $\mathrm{ms}$ ) when comparing the A and VA conditions. This effect reached a statistically significant level only for the 55\% middle visual contrast (paired t-test, $\mathrm{p}=0.009$ ). In this condition, the mean latency was $64.5 \mathrm{~ms}$ in the unimodal visual stimulation against $61.0 \mathrm{~ms}$ in the VA condition, corresponding to a global decrease of more than $5 \%$.

At $15 \%$ contrast, the VA stimulation lead to similar values of latency compared to the V-only task ( $96.8 \mathrm{~ms}$ vs 100.7 ms respectively), a difference which was not statistically significant (paired t-test, $\mathrm{p}=0.43 \mathrm{~ns}$ ) probably because of a greater variability in the measured latency due to a strong reduction in the cell discharge (see above) when presenting this low contrast visual stimulus.

Finally, at high contrast (88\%) the neurons showed very comparable latencies (49.0 in VA vs $49.2 \mathrm{~ms}$ in V-only, paired t-test, $\mathrm{p}=0.82 \mathrm{~ns}$ ).

The decrease in latency at the mid contrast level did not similarly affect all visual cells in V1. A correlation analysis

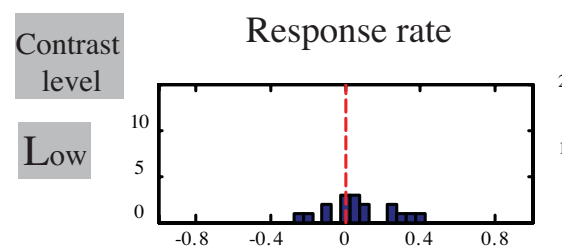

Response latency
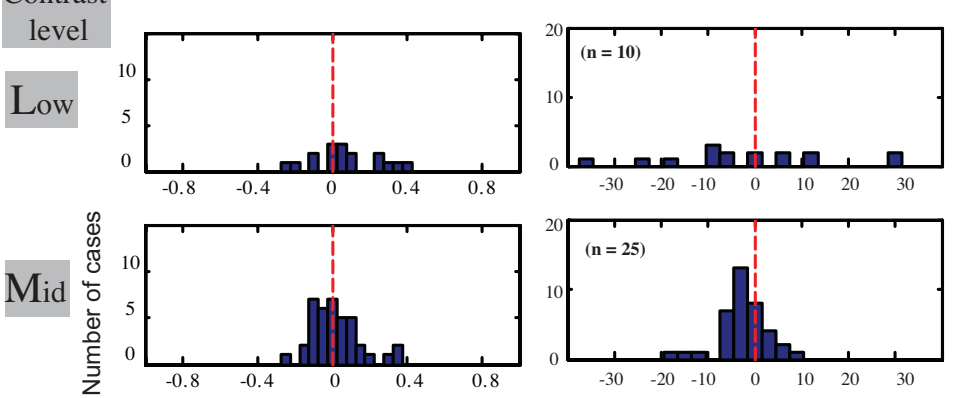

High

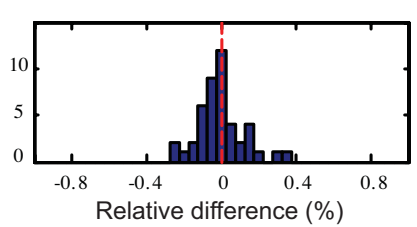

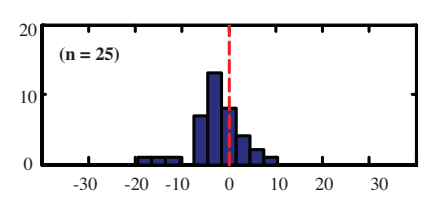

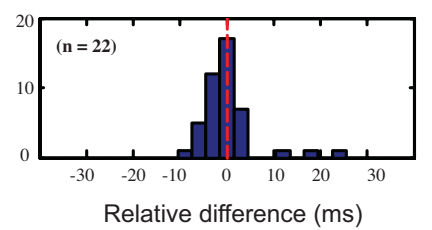

Averaged response

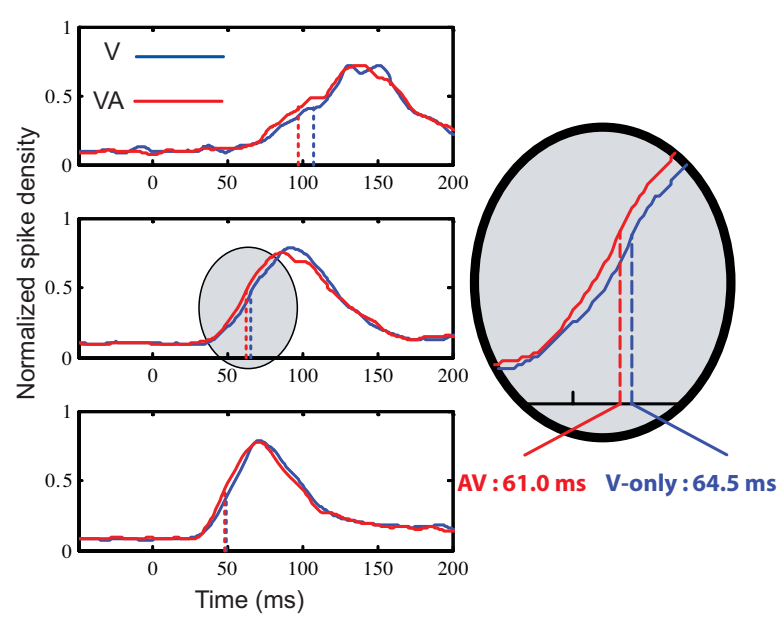

Figure 4

Effects of a visuo-auditory stimulus on the visual responses obtained from 49 single units recorded in $\mathrm{VI}$ during a visuo-auditory saccadic task performed at three contrast levels ( $15 \%$, upper row, $55 \%$, middle row and $\mathbf{8 8} \%$, lower row). The right panels represent the averaged normalized responses of the cells population during the $\mathrm{V}$-only (blue) or visuo-auditory (red) conditions. The other panels show the distribution of the relative difference in the response rates (left) or latencies (middle) of the cells when the V-only and VA conditions are compared for each individual cell. A value of "0" means no difference, while negative values represent a decrease in the VA compared to V-only condition. At high and mid-contrasts no effects are observed concerning the response rate, while we observed a shift of the distribution of latencies toward negative values, indicating a shortening of the visual latency during the bimodal condition. The numbers of cells showing a reduction in latency are indicated in the brackets. 
Table 2: Response rates and latency values ( \pm se) of $\mathrm{VI}$ single units recorded during the V/VA passive tasks and the $\mathrm{V}$-only control task using a middle $(55 \%)$ contrast value.

\begin{tabular}{ccccc}
\hline & \multicolumn{2}{c}{ Passive task } & \multicolumn{2}{c}{ Visual control task } \\
\cline { 2 - 5 } & V-only & AV & Visual Fixation & Visual Saccade \\
\hline Response Rate (spk/s) & $29.5 \pm 2.6$ & $29.8 \pm 2.8$ & $28.7 \pm 2.3$ & 29.42 .2 \\
Latency (ms) & $65.0 \pm 4.7$ & $65.2 \pm 4.3$ & $44.0 \pm 1.4$ & $43.5 \pm 1.5$ \\
\hline
\end{tabular}

between the absolute latency values in the V-only condition and the relative change (in ms) that occurred during the VA stimulation, revealed an inverse relationship $(\mathrm{r}=-$ $0.4, \mathrm{p}=0.01$, Pearson test, see Figure 5). This means that the cells with the longer latency showed a greater reduction in the bimodal condition, a mechanism that consequently should globally increase the rate of visual processing in area V1. In the other visual conditions (high and low contrasts), the correlation analysis did not reach a statistically significant level (both cases, $\mathrm{p}>0.05$ ).

To conclude, we observed that the concomitant presentation of an auditory signal simultaneously with a saccadic visual target induced a reduction of the latency of V1 cells that depended on the contrast of the visual target. Furthermore, the discharge rates of the neurons remained unaffected by bimodal stimulation except during visual conditions that approach the perceptive threshold.

Absence of visuo-auditory interactions in the V/VA passive tasks We analyzed the effect of a visuo-auditory stimulus on the activity of a different set of $45 \mathrm{~V} 1$ neurons in a passive task

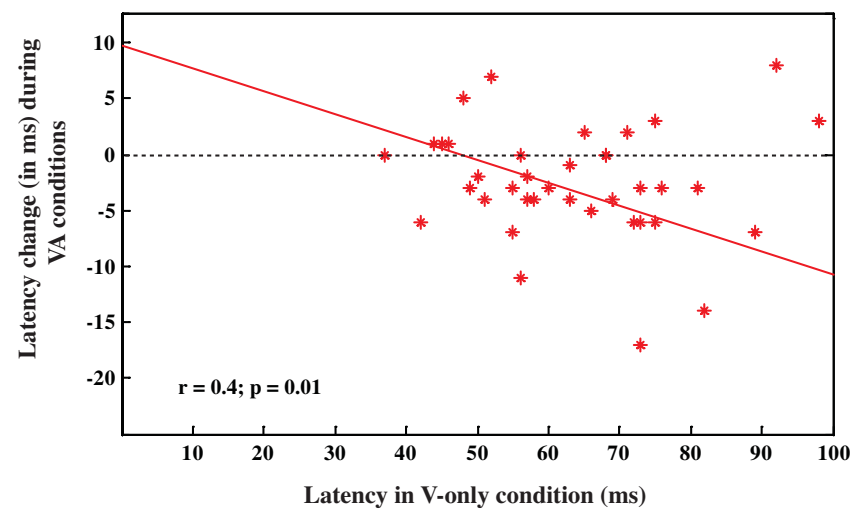

Figure 5

Relationship between the latencies of the cells in the $\mathrm{V}$-only active task and their respective changes (in ms) when tested in the AV active task. We observed a statistical inverse relation ( $P=0.01$; Pearson test) corresponding to a larger reduction for the cells showing longer response latencies. during which the monkey maintained a central fixation while the peripheral stimulus was delivered in the cell's RF. In this case, the results were quite simple in that at all contrasts tested, we did not observe a change in the visual response with the spatially congruent auditory stimulus (Table 2, fig 6). First, the response rate remained unchanged between the V-only and VA conditions (29.5 and $29.8 \mathrm{spk} / \mathrm{s}$ respectively, paired t-test, $\mathrm{p}=0.69 \mathrm{~ns}$ ) as reported in the active task. However, in contrast to the effects observed in the saccadic task, the cell visual latencies were the same in the two conditions $(65.0 \mathrm{~ms}$ in Vonly vs. $65.2 \mathrm{~ms}$ in VA condition, paired t-test, $\mathrm{p}=0.95$ ns). These results are presented in Fig 6 as the relative changes in discharge rate and latency values, and the distributions are well centered on zero, indicating no difference between the two conditions.

In a subset of neurons $(n=29)$, we also searched for an effect of the auditory stimulus alone on the neurons activity during a simple central fixation (Fig 7). We did not observe any auditory response. Following a single sound presentation the firing rate of the single cells remained at the same level as the spontaneous activity (paired t-test, $\mathrm{p}$ $=0.9056$, non significant).

Visual responses in the V-only control task

Previous studies in the behaving monkey have shown that neuronal responses in striate and extrastriate cortical areas can be modulated by the behavioral meaning of the stimulus $[57,58]$. Consequently, we compared the visual responses of a third set of $\mathrm{V} 1$ single units $(\mathrm{n}=42)$ during a dual task, a passive central fixation and an active visually guided saccadic task. As explained in the methods, the type of task was indicated to the animal by the color of the fixation point. In this case (Table 2, Fig 6), we did not observe an effect of the task (passive vs. active) either on the frequency discharge (28.7 and $29.4 \mathrm{spk} / \mathrm{s}$ respectively, paired t-test, $\mathrm{p}=0.25 \mathrm{~ns}$ ) or on the visual latency (44.0 and $43.5 \mathrm{~ms}$ respectively, paired t-test, $\mathrm{p}=0.70 \mathrm{~ns}$ ). This last part suggests that the visuo-auditory interactions that differentially affected the cells in the previous conditions were probably not due to the oculomotor demands of the task in which the monkey was engaged. 

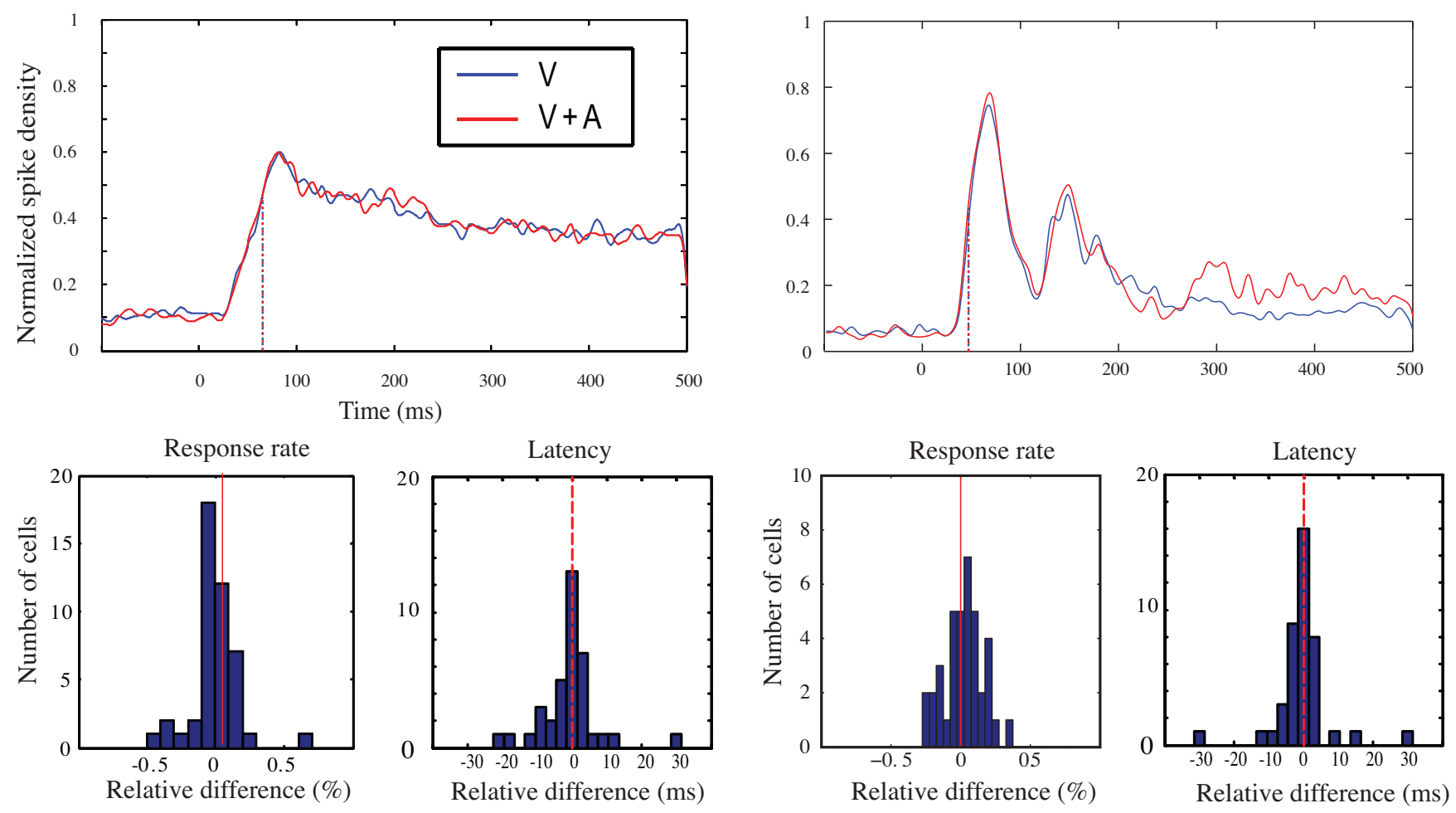

\section{V/VA Passive task}

\section{V-only control task}

\section{Figure 6}

Left: effects of a visuo-auditory stimulus on the visual responses obtained from $45 \mathrm{VI}$ single units recorded during a passive visuo-auditory task. No effects are observed either on the response rate or on the visual latency. Right: absence of an effect of the behavioral paradigm on the activity of $42 \mathrm{VI}$ neurons during the visual-only condition. When comparing the neuronal activity of the same cells during a visual passive fixation task to a visual saccadic task, we did not observe a modulation of the response rate or response latency. Conventions as in Figure 5.

\section{Discussion}

The present results demonstrate that in behaving monkeys visuo-auditory interaction can occur at the single cell level at the first cortical stage of processing of visual information, the primary visual cortex V1. Multisensory interactions in $\mathrm{V} 1$ are characterized in our experiment by a modulation of $\mathrm{V} 1$ responses corresponding to a reduction of the neuronal onset latency. Moreover this effect was dependent on the perceptual charge of the task in which the animal was engaged.

\section{Visuo-auditory interaction: behavioral evidence}

We show that the simultaneous presentation of a sound during a visually guided saccade, induces a reduction of about 10 to $15 \%$ in the saccade latency depending on the animal and on the visual stimulus contrast level. Such behavioral improvement resulting from a bimodal visuoauditory stimulation has been already reported during similar paradigms of spatially oriented behavior in humans [54,59-61], monkeys [50,59], carnivores [62,63] and even in rodents or birds [64,65]. Numerous studies have established the beneficial effect of bimodal stimulation [66] when the experimental sensory conditions respect the rules of spatial and temporal congruencies [55]. In these cases, multisensory integration results in perceptual improvements by reducing ambiguity in various tasks, from simple detections to complex discriminations, memory or learning tasks [67-71]. The decrease in reaction times during a bimodal paradigm has been explained by a co-activation system [72] that violates the race model of independent sensory channels in which the faster modality initiates the motor response. In our study, we did not train the animals to make a saccade toward an isolated auditory cue, so we cannot conclude on the race model. However, we recently reported evidence that such a converging model can account for a shortening in RT in visuo-auditory detection task in the monkey [23].

Multisensory integration is supposed to obey the rule of inverse effectiveness that proposes a higher multisensory 

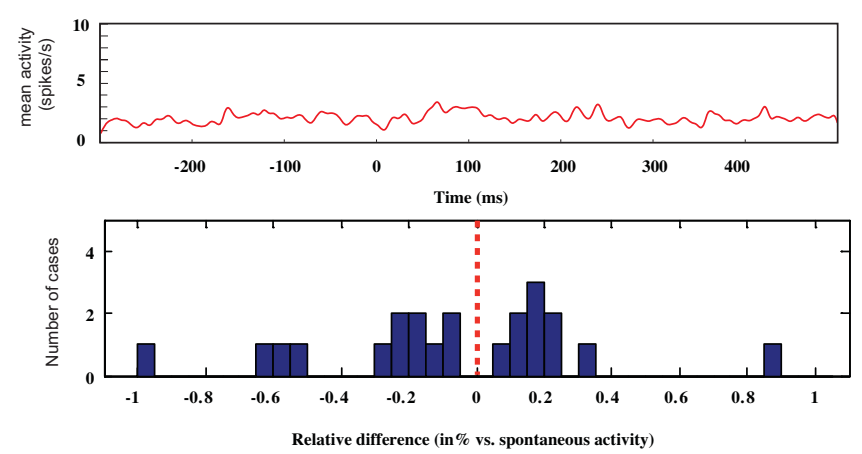

Figure 7

Average activity of $29 \mathrm{VI}$ single cells following the passive presentation of an auditory stimulus. The upper graph shows the average activity of the entire population. No response can be observed following the 25 ms presentation of the broad band noise at time 0 . This is also apparent in the lower graph that compares the relative difference of the neuronal activity before and during the auditory presentation. No statistical differences were obtained (see text) confirming the lack of auditory response.

benefit when the unisensory stimuli are weak $[62,73]$. We did not observe such effects and the decrease in sRT was identical when comparing visuo-auditory performances at low or high visual saliencies, a result comparable to that recently reported in a similar behavioral study in the monkey)[50]. We cannot rule out the possibility that if we had used a weaker auditory stimulus it would have produced a change in bimodal gains [23], but it is very likely that this lack of inverse effectiveness is due to the fact that our experiments were performed on highly trained monkeys. It has been shown in monkey, that a continuous training strongly decreases the saccade latency [74], probably reducing the potential range of facilitation induced by the mechanisms of multisensory integration.

\section{Multisensory interaction at early stages of sensory processing}

The delimitation of the polymodal areas associated with multisensory integration was until recently, generally circumscribed to cortical areas in the parietal, frontal and inferotemporal regions of the monkey $[5,38,75-77]$. However, electrophysiological and functional imaging studies in humans have recently revealed that visual, somatosensory or auditory areas defined originally as unimodal can be the locus of interactions between other non-specific sensory modalities [13,16-18,78-81]. In the monkey, electrophysiological recordings have confirmed that unimodal areas, located at the first stages of the sensory processing hierarchy, can integrate information from a different sensory channel [11].
Until recently, this heteromodal activity had been observed in primates principally in the auditory system. For example, recordings of neuronal activity in the auditory cortex have revealed visual and somatosensory responses in the associative areas of the belt and parabelt $[25,27,28,82,83]$. In the primary auditory cortex, electrophysiological recordings (current source density) suggest that non-auditory events are of a rather modulatory influence and do not drive activation at the spiking level [84]. For example, proprioceptive information (eye position) can induce changes in the strength of the neuronal discharge in response to a spatially defined sound [29]. Furthermore, it has been proposed that the effect of nonauditory stimuli on AI activity is performed through a modulation of cortical oscillations to allow either enhancement or depression, depending on the timing of the bimodal stimulation [84]. Our results are in agreement with this notion of a modulatory effect and we did not find any auditory response in the single units we tested. The lack of pure auditory response in spite of an auditory modulation of the visual latency suggests that in V1, multisensory interaction could be a subthreshold phenomenon as hypothetized for multisensory interactions in the auditory cortex $[24,83]$. Because the auditory system is activated faster than the visual one, the auditory stimulus can depolarize the membrane potential of the visual V1 cells, inducing an earlier spiking response compared to the visual-only condition. Such multisensory interaction on cortical sensitivity has been recently suggested by TMS studies in human at both perceptual [85] and behavioral [86] levels.

The main visuo-auditory effect we observed, was a shortening of the visual latencies but only in specific behavioral situations. All together these results suggest that in primates, multisensory integration mechanisms differentially affect sensory responses when they occur in primary or secondary sensory areas $[11,24,87-90]$.

Most of the neuronal rules of interactions between sensory modalities have been established in the Superior colliculus (SC) which is considered to be the key structure for multisensory integration [55]. In the SC, the convergence of different sensory modalities is reflected mainly by an enhancement in neuronal activity in response to a combined multimodal stimulus when spatial and temporal congruencies are respected [91-94]. A modulation (enhancement or depression) of the strength of the unimodal response by bimodal stimulation has been also reported in higher order polymodal areas of the monkey such as the prefrontal, parietal or inferotemporal areas $[75,77,95,96]$ and even in the primary auditory cortex $[24,84,97]$. However, the proportion of neurons showing enhancement or depression varies strongly across cortical areas. When presenting middle or high contrast visual 
stimuli, we did not observe such an effect on the response rate in the large sample of visual cells recorded in V1, irrespective of the behavioral paradigm, suggesting that the neuronal mechanisms of multisensory integration are based on rules which are specific to each individual area. However, at low (15\%) contrast, the slight increase of the responsiveness of $\mathrm{V} 1$ neurons in the $\mathrm{AV}$ condition suggests that the rule of inverse effectiveness could apply to V1. We cannot exclude that such effect on the response rate would be more prominent for visual stimuli of even lower perceptive saliency.

In addition, as described in the methods, the visual and auditory stimuli are only spatially congruent in the horizontal azimuth dimension. While the receptive fields of the auditory neurons are large [98] and cover probably the offset that separate the two stimuli, one can speculate that a better spatial congruency between the auditory and visual stimuli would lead to greater effects on V1 cells during bimodal stimulation.

Finally, a rule common to several cerebral loci of multisensory integration is an effect on the response onset latency $[75,99]$. We observed that in the active task, the visual latency was reduced by about $5 \%$, a result very similar to that reported in the SC $[50,99]$. This decrease in neuronal response onset, which is in line with a shortening of the visuo-auditory bold response in human V1 assessed by fMRI [13], could participate in the speeding up of the behavioral saccadic responses during bimodal presentation (see below, [62]).

As developed in the introduction, previous anatomical studies have established that sensory fusion was processed through the convergence of the different sensory channels at the level of associative cortical areas $[1,2]$. The numerous reports of multisensory interactions at low level of sensory processing (present data, $[24,27,84]$ ) and acting on early sensory responses, favor a modulatory influence through heteromodal connections linking directly unisensory areas [19-21]. However, such modulatory effect could also originate from non-specific thalamic nuclei that integrate different sensory processing [100]. A cortico-thalamic loop that bypass cortico-cortical connections could thus support fast transmission and provide multisensory and sensory-motor information to unimodal areas $[22,101]$.

\section{Visuo-auditory interaction: role of the behavioral context} In the alert monkey, we have shown that visual neurons in V1 showed a decrease in response onset when the visual stimuli were presented simultaneously with a sound. However, our main result is that this effect on the visual responses is dependent on the behavioral context : we did not see any changes in V1 neuron latency in a passive sit- uation when the monkey did not perform an oriented saccade toward the spatial location where the auditory stimulus was presented. It could be argued that this difference simply reflects a process of visual spatial attention [102] due to the oculomotor task and not a modulation specifically due to the integration of the auditory stimulus at the neuronal level. In V1 and extra-striate areas, it has been shown that attentional mechanisms [103,104] or behavioral relevance $[57,105,106]$ can affect the characteristics of the neuronal visual response such as the discharge rate, the latency or the neurons selectivity. We did not observe a change in the cell firing rate when comparing neuronal activity in a visual passive and active task without any auditory stimuli. While our comparisons are performed on a different set of neurons, it strongly suggests that the shortening in latency depends specifically on the bimodal conditions in a particular behavioral situation, and not on visual attentional processes linked to the oculomotor demand of the task. However, we are aware that the three paradigms differ in term of attentional loads but in both passive and active AV tasks, the auditory stimulus can involve similar mechanisms of exogenous attention. The distinction between exogenous spatial attention and crossmodal interactions (or integration) is still an open question [107] as both mechanisms result in an improvement in sensory perception [102].

Our results are in complete agreement with studies in humans and animals showing different patterns of multisensory integration according to the behavioral context. First in humans, the detection or discrimination of bimodal objects, as well as the perceptual expertise of subjects, differentially affect both the temporal aspects and the cortical areas at which multisensory interactions occur $[18,108]$. Similarly the index of multisensory integration computed from the activity of neurons in the deep layers of the Superior Colliculus, is also dependent on the oculomotor behavior of the animal [109]. Finally, while heteromodal visual or somatosensory responses can be obtained in the auditory cortex of a passive or anaesthetized monkey $[24,27,87]$, some authors have reported that some visual responses can be related to task in which the animal is engaged [25].

All together these findings suggests that the neuronal network involved in multisensory integration as well as its expression at the level of the neuronal activity is highly dependent on the perceptual task in which the subject is engaged. Thus multisensory interactions can underly from active perception to attentional mechanisms. This hypothesis is supported by the anatomical pattern of heteromodal connections that directly link areas involved in different modalities. In monkey, such heteromodal connections either link specific sensory representations 
(retinotopy or somatotopy) of interconnected areas or specific functional regions in each modality $[19,21,110]$.

Such an influence of the perceptual context on the neuronal expression of multisensory interaction has further consequences on the phenomena of cross-modal compensation that occurs after sensory deprivation in animals [111] or humans [112,113]. In blind subjects [114], the efficiency of somatosensory stimulation on the activation of the visual cortex, is maximum during an active discrimination task (Braille reading). This suggests that the mechanisms of multisensory interaction at early stages of sensory processing and the cross-modal compensatory mechanisms are probably mediated through common neuronal pathways.

\section{Role of visuo-auditory integration in the primary visual cortex} The effect of an auditory stimulus on V1 responses is probably supported through the direct projections that originate in the auditory (A1 and belt) and multimodal (STP) areas and target V1 $[20,21]$. As discussed previously [21], the auditory projections to V1 originate mainly from the dorsal auditory stream, specialized in processing spatial information, and reach the peripheral representation of V1. The characteristics of this heteromodal connectivity suggest that this pathway is probably involved in rapidly orienting the gaze toward a sound source located in the peripheral field for which visual acuity is poor. In situations of spatial and temporal congruency, multisensory integration has been shown to facilitate the neuronal responses of neurons of the superior colliculus $[115,116]$, both at the sensory and motor levels [50,59]. Consequently, multisensory integration at the collicular level will allow a direct influence on motor output because the SC is directly involved in the control of oculomotor behavior [117]. A large number of visual areas project directly down to the SC, but in the monkey, the main inputs are originating from the primary visual cortex which constitutes about 20 to $30 \%$ of the SC cortical afferents [118]. Consequently the decrease in V1 response latencies during bimodal stimulation can act directly on the response of cells in the SC and speed up the initiation of the saccadic command by the brain stem oculomotor nucleus. However, because the reduction in V1 latencies (5\% decrease) does not match the amount of facilitation at the saccadic level (10 to $15 \%$ reduction in saccade latency), one should consider other mechanisms outside $\mathrm{V} 1$, to transfer the facilitation from the sensory to the motor level.

A remaining question is whether the visuo-auditory interactions reported here at the level of $\mathrm{V} 1$ and expressed as a reduction in neuronal latency, represent a real multisensory integration or only a sensory combination [119]. In our protocol, auditory and visual stimuli are not redun- dant signals as the sound has no meaning to perform the task and thus in this way, we should refer to bimodal interactions in V1. However, at the behavioral level, the observed shortening of saccade latency in the bimodal conditions is a phenomenon generally attributed to multisensory integration processing [72]. It is possible that the reduction in latency, especially because it affects mainly the longer ones, will induce a higher temporal coherence of the visual responses across V1. Such a processing has been suggested to increase the cortical synchronization which in turn enhances the speed and reliability of the visual responses [120], and thus could participate to the reduction of RT in bimodal conditions.

\section{Conclusion}

To conclude, our results provide further evidence of the various roles of monkey area V1 in visual perception. Area $\mathrm{V} 1$ receives feedback projections from a large number of cortical areas [121]. V1 is connected with areas located at higher levels of the visual processing hierarchy [122,123], with non-visual sensory areas as described above, as well as with the area prostriata [124] which might constitute a gateway to the motor system [125]. This connectivity pattern could be the anatomical support of the neuronal modulation of $\mathrm{V} 1$ responses by higher cognitive processes such as attention mechanisms [126,127] or memory tasks $[128,129]$. The present results suggest that multisensory integration should be added to the list of cognitive processes performed in V1.

\section{Authors' contributions}

YW carried out all experiments and performed statistical analysis. YW, SC, YT and BP participated in the design of the study, the data analysis and wrote the manuscript. All authors read and approved the final manuscript.

\section{Acknowledgements}

We thank F. Lefevre et S. Aragones for care of the animal, C. Marlot for her precious work on the bibliography data base, and L. Reddy for corrections on the manuscript. Grant Support. The CNRS Atipe program (YW and $\mathrm{BP}$ ), the CNRS Robea program (YT, SC, BP).

\section{References}

I. Jones EG, Powell TP: An anatomical study of converging sensory pathways within the cerebral cortex of the monkey. Brain 1970, 93(4):793-820.

2. Masterton RB, Berkley MA: Brain function: changing ideas on the role of sensory, motor, and association cortex in behavior. Annu Rev Psychol 1974, 25:277-3 I2.

3. Poremba A, Saunders RC, Crane AM, Cook M, Sokoloff L, Mishkin M: Functional mapping of the primate auditory system. Science 2003, 299(5606):568-572.

4. Bremmer F, Schlack A, Shah NJ, Zafiris O, Kubischik M, Hoffmann K, Zilles K, Fink GR: Polymodal motion processing in posterior parietal and premotor cortex: a human fMRI study strongly implies equivalencies between humans and monkeys. Neuron 200I, 29(I):287-296.

5. Graziano MS: A system of multimodal areas in the primate brain. Neuron 200I, 29(I):4-6. 
6. Graziano MS, Gandhi S: Location of the polysensory zone in the precentral gyrus of anesthetized monkeys. Exp Brain Res 2000, 135(2):259-266.

7. Downar J, Crawley AP, Mikulis DJ, Davis KD: A multimodal cortical network for the detection of changes in the sensory environment. Nat Neurosci 2000, 3(3):277-283.

8. Mistlin AJ, Perrett DI: Visual and somatosensory processing in the macaque temporal cortex: the role of 'expectation'. Exp Brain Res 1990, 82(2):437-450.

9. Baylis GC, Rolls ET, Leonard CM: Functional subdivisions of the temporal lobe neocortex. J Neurosci 1987, 7(2):330-342.

10. Ghazanfar AA, Schroeder CE: Is neocortex essentially multisensory? Trends Cogn Sci 2006, I 0(6):278-285.

II. Schroeder CE, Foxe J: Multisensory contributions to low-level, 'unisensory' processing. Curr Opin Neurobiol 2005, I 5(4):454-458.

12. Kaas J, Collins CE: The resurrection of multisensory cortex in primates: connection patterns that integrates modalities. In The handbook of multisensory processes Edited by: Calvert G, Spence C Stein BE. Cambridge, Mass.: MIT Press; 2004:285-293.

13. Martuzzi R, Murray MM, Michel CM, Thiran JP, Maeder PP, Clarke S, Meuli RA: Multisensory Interactions within Human Primary Cortices Revealed by BOLD Dynamics. Cereb Cortex 2007, I7(7):1672-1679.

14. Laurienti PJ, Wallace MT, Maldjian JA, Susi CM, Stein BE, Burdette JH: Cross-modal sensory processing in the anterior cingulate and medial prefrontal cortices. Hum Brain Mapp 2003, 19(4):2। 3-223.

15. Calvert GA, Campbell R, Brammer MJ: Evidence from functional magnetic resonance imaging of crossmodal binding in the human heteromodal cortex. Curr Biol 2000, I (II):649-657.

16. Sathian K, Zangaladze A, Hoffman JM, Grafton ST: Feeling with the mind's eye. Neuroreport 1997, 8(18):3877-388I.

17. Foxe J], Morocz IA, Murray MM, Higgins BA, Javitt DC, Schroeder CE: Multisensory auditory-somatosensory interactions in early cortical processing revealed by high-density electrical mapping. Brain Res Cogn Brain Res 2000, I 0(I-2):77-83

18. Giard $\mathrm{MH}$, Peronnet $\mathrm{F}$ : Auditory-visual integration during multimodal object recognition in humans: a behavioral and electrophysiological study. J Cogn Neurosci 1999, I I (5):473-490.

19. Cappe C, Barone P: Heteromodal connections supporting multisensory integration at low levels of cortical processing in the monkey. Eur J Neurosci 2005, 22(I I):2886-2902

20. Rockland $\mathrm{KS}$, Ojima $\mathrm{H}$ : Multisensory convergence in calcarine visual areas in macaque monkey. Int J Psychophysiol 2003, 50(I2): 19-26.

21. Falchier A, Clavagnier S, Barone P, Kennedy H: Anatomical evidence of multimodal integration in primate striate cortex. Neurosci 2002, 22(I3):5749-5759.

22. Hackett TA, De La Mothe LA, Ulbert I, Karmos G, Smiley J, Schroeder CE: Multisensory convergence in auditory cortex, II. Thalamocortical connections of the caudal superior temporal plane. J Comp Neurol 2007, 502(6):924-952.

23. Cappe C, Loquet G, Barone P, Rouiller E: Influences of auditory and visual stimuli on neurons in auditory cortical areas in monkeys performing an audio-visual detection task. In Society for Neuroscience: 2007 San diego; 2007.

24. Kayser C, Petkov Cl, Logothetis NK: Visual modulation of neurons in auditory cortex. Cereb Cortex 2008, I8(7): I560-1574.

25. Brosch M, Selezneva E, Scheich H: Nonauditory events of a behavioral procedure activate auditory cortex of highly trained monkeys. I Neurosci 2005, 25(29):6797-6806.

26. Schroeder CE, Smiley J, Fu KG, McGinnis T, O'Connell MN, Hackett TA: Anatomical mechanisms and functional implications of multisensory convergence in early cortical processing. Int J Psychophysiol 2003, 50( I-2):5-17.

27. Fu KM, Johnston TA, Shah AS, Arnold L, Smiley J, Hackett TA, Garraghty $\mathrm{PE}$, Schroeder CE: Auditory cortical neurons respond to somatosensory stimulation. J Neurosci 2003, 23(20):75 I0-75। 5 .

28. Schroeder CE, Lindsley RW, Specht C, Marcovici A, Smiley JF, Javitt DC: Somatosensory input to auditory association cortex in the macaque monkey. J Neurophysiol 200I, 85(3): I322-I 327

29. Werner-Reiss U, Kelly KA, Trause AS, Underhill AM, Groh JM: Eye position affects activity in primary auditory cortex of primates. Curr Biol 2003, I 3(7):554-562.

30. Bulkin DA, Groh JM: Seeing sounds: visual and auditory interactions in the brain. Curr Opin Neurobiol 2006, 16(4):415-4I9.
31. Fishman MC, Michael P: Integration of auditory information in the cat's visual cortex. Vision Res 1973, 13(8): 1415-1419.

32. Spinelli DN, Starr A, Barrett TW: Auditory specificity in unit recordings from cat's visual cortex. Exp Neurol 1968, 22(I):75-84.

33. Murata K, Cramer H, Bach-y-Rita P: Neuronal convergence of noxious, acoustic, and visual stimuli in the visual cortex of the cat. J Neurophysiol I965, 28(6): I223-I239.

34. Sanchez-Vives MV, Nowak LG, Descalzo VF, Garcia-Velasco JV, Gallego R, Berbel P: Crossmodal audio-visual interactions in the primary visual cortex of the visually deprived cat: a physiological and anatomical study. Prog Brain Res 2006, I55:287-3 II.

35. Trotter Y, Celebrini S: Gaze direction controls response gain in primary visual-cortex neurons. Nature 1999, 398(6724):239-242.

36. Trotter Y, Celebrini S, Stricanne B, Thorpe S, Imbert M: Modulation of neural stereoscopic processing in primate area $\mathrm{VI}$ by the viewing distance. Science 1992, 257(5074): 1279-|28|.

37. Recanzone GH, Guard DC, Phan ML: Frequency and intensity response properties of single neurons in the auditory cortex of the behaving macaque monkey. I Neurophysiol 2000, 83(4):23|5-233|.

38. Bruce C, Desimone R, Gross CG: Visual properties of neurons in a polysensory area in superior temporal sulcus of the macaque. J Neurophysiol I98I, 46(2):369-384.

39. Nowak LG, Bullier ]: The timing of information transfer in the visual system. In Extrastriate visual cortex in primates Volume 12. Edited by: Kaas JH, Rockland KL, Peters AL. Plenum Pub Corp; 1997:205-24|

40. Nowak LG, Munk MH, Girard P, Bullier J: Visual latencies in areas VI and V2 of the macaque monkey. Vis Neurosci 1995, I 2(2):37|-384

4I. Maunsell JH, Gibson JR: Visual response latencies in striate cortex of the macaque monkey. I Neurophysiol 1992, 68(4): $1332-1344$

42. Recanzone GH: Spatial processing in the auditory cortex of the macaque monkey. Proc Natl Acad Sci USA 2000, 97(22): I I829-II 1835

43. Barone $\mathrm{P}$, Clarey JC, Irons WA, Imig TJ: Cortical synthesis of azimuth-sensitive single-unit responses with nonmonotonic level tuning: a thalamocortical comparison in the cat. J Neurophysiol 1996, 75(3): I 206-1220.

44. Durand JB, Zhu S, Celebrini S, Trotter Y: Neurons in parafoveal areas $\mathrm{VI}$ and V2 encode vertical and horizontal disparities. Neurophysiol 2002, 88(5):2874-2879.

45. Takahashi TT, Keller CH, Nelson BS, Spitzer MW, Bala AD, Whitchurch EA: Object localization in cluttered acoustical environments. Biol Cybern 2008, 98(6):579-586.

46. Litovsky RY, Colburn HS, Yost WA, Guzman SJ: The precedence effect. J Acoust Soc Am 1999, I06(4 Pt I): 1633-1654.

47. Daniel PM, Whitteridge $D$ : The representation of the visual field on the cerebral cortex in monkeys. J Physiol I96I, I 59:203-22I.

48. Durand JB, Celebrini S, Trotter Y: Neural bases of stereopsis across visual field of the alert macaque monkey. Cereb Cortex 2007, 17(6): 1260-1273

49. Lu SM, Guido W, Vaughan JW, Sherman SM: Latency variability of responses to visual stimuli in cells of the cat's lateral geniculate nucleus. Exp Brain Res 1995, 105(1):7-17.

50. Bell AH, Meredith MA, Van Opstal Al, Munoz DP. Crossmodal Integration in the Primate Superior Colliculus Underlying the Preparation and Initiation of Saccadic Eye Movements. Neurophysiol 2005, 93(6):3659-3673.

5I. Bell AH, Meredith MA, Van Opstal AJ, Munoz DP: Stimulus intensity modifies saccadic reaction time and visual response latency in the superior colliculus. Exp Brain Res 2006, 174(1):53-59.

52. Frens MA, Van Opstal AJ, Willigen RF Van der: Spatial and temporal factors determine auditory-visual interactions in human saccadic eye movements. Percept Psychophys 1995, 57(6):802-816.

53. Boch R, Fischer B, Ramsperger E: Express-saccades of the monkey: reaction times versus intensity, size, duration, and eccentricity of their targets. Exp Brain Res 1984, 55(2):223-23I.

54. Goldring JE, Dorris MC, Corneil BD, Ballantyne PA, Munoz DP: Combined eye-head gaze shifts to visual and auditory targets in humans. Exp Brain Res 1996, I I I(1):68-78. 
55. Stein BE, Meredith MA: The merging of the senses Cambridge, Mass.: MIT Press; 1993.

56. Gawne TJ, Kjaer TW, Richmond BJ: Latency: another potential code for feature binding in striate cortex. J Neurophysiol 1996 , 76(2): $1356-1360$

57. Robinson DL, Baizer JS, Dow BM: Behavioral enhancement of visual responses of prestriate neurons of the rhesus monkey. Invest Ophthalmol Vis Sci 1980, 19(9): I I20-I I 23.

58. Wurtz RH, Mohler CW: Enhancement of visual responses in monkey striate cortex and frontal eye fields. J Neurophysiol 1976, 39(4):766-772.

59. Frens MA, Van Opstal AJ: Visual-auditory interactions modulate saccade-related activity in monkey superior colliculus. Brain Res Bull 1998, 46(3):2 I I-224.

60. Frens MA, Van Opstal A): A quantitative study of auditoryevoked saccadic eye movements in two dimensions. Exp Brain Res 1995, 107(1):103-117.

61. Hughes HC, Reuter-Lorenz PA, Nozawa G, Fendrich R: Visual-auditory interactions in sensorimotor processing: saccades versus manual responses. J Exp Psychol Hum Percept Perform 1994, 20(1):|3|-|53.

62. Stein BE, Huneycutt WS, Meredith MA: Neurons and behavior: the same rules of multisensory integration apply. Brain Res 1988, 448(2):355-358

63. Stein BE, Meredith MA, Huneycutt WS, Mcdade L: Behavioral indices of multisensory integration: orientation to visual cues is affected by auditory stimuli. J Cogn Neurosci 1989, I(I): 12-24.

64. Whitchurch EA, Takahashi TT: Combined auditory and visua stimuli facilitate head saccades in the barn owl (Tyto alba). J Neurophysiol 2006, 96(2):730-745.

65. Sakata S, Yamamori T, Sakurai Y: Behavioral studies of auditoryvisual spatial recognition and integration in rats. Exp Brain Res 2004, I 59(4):409-4I7.

66. Welch RB, Warren DH: Intersensory interactions. In Handbook of perception and human performance Volume I. Edited by: Boff KR, Kaufman L, Thomas JP. New York: Wiley; I 986:I-36.

67. Seitz AR, Kim R, Shams L: Sound facilitates visual learning. Cur Biol 2006, I6( I 4): 1422-1427.

68. Lehmann S, Murray MM: The role of multisensory memories in unisensory object discrimination. Brain Res Cogn Brain Res 2005 24(2):326-334.

69. Lovelace CT, Stein BE, Wallace MT: An irrelevant light enhances auditory detection in humans: a psychophysical analysis of multisensory integration in stimulus detection. Brain Res Cogn Brain Res 2003, 17(2):447-453.

70. Vroomen J, de Gelder B: Sound enhances visual perception: cross-modal effects of auditory organization on vision. J Exp Psychol Hum Percept Perform 2000, 26(5): I583-1590.

71. McDonald JJ, Teder-Salejarvi WA, Hillyard SA: Involuntary orienting to sound improves visual perception. Nature 2000 407(6806):906-908.

72. Miller J: Divided attention: evidence for coactivation with redundant signals. Cognit Psychol 1982, I4(2):247-279.

73. Ross LA, Saint-Amour D, Leavitt VM, Javitt DC, Foxe J]: Do You See What I Am Saying? Exploring Visual Enhancement of Speech Comprehension in Noisy Environments. Cereb Cortex 2006, I7: I 147-II53.

74. Boch R, Fischer B: Saccadic reaction times and activation of the prelunate cortex: parallel observations in trained rhesus monkeys. Exp Brain Res 1983, 50(2-3):201-210.

75. Avillac M, Ben Hamed S, Duhamel JR: Multisensory integration in the ventral intraparietal area of the macaque monkey. J Neurosci 2007, 27(8): 1922-1932.

76. Schlack A, Sterbing-D'Angelo SJ, Hartung K, Hoffmann KP, Bremmer F: Multisensory space representations in the macaque ventral intraparietal area. J Neurosci 2005, 25( I 8):4616-4625.

77. Barraclough NE, Xiao D, Baker Cl, Oram MW, Perrett DI: Integration of visual and auditory information by superior temporal sulcus neurons responsive to the sight of actions. / Cogn Neurosci 2005, |7(3):377-39|.

78. Pekkola J, Ojanen V, Autti T, Jaaskelainen IP, Mottonen R, Tarkiainen A, Sams M: Primary auditory cortex activation by visual speech: an fMRI study at 3 T. Neuroreport 2005, I 6(2): I 25-I 28.

79. Murray MM, Molholm S, Michel CM, Heslenfeld DJ, Ritter W, Javitt DC, Schroeder CE, Foxe J]: Grabbing Your Ear: Rapid AuditorySomatosensory Multisensory Interactions in Low-level Sen- sory Cortices Are Not Constrained by Stimulus Alignment. Cereb Cortex 2005:963-974.

80. Molholm S, Ritter W, Murray MM, Javitt DC, Schroeder CE, Foxe J]: Multisensory auditory-visual interactions during early sensory processing in humans: a high-density electrical mapping study. Brain Res Cogn Brain Res 2002, I 4( I): I I5-I28.

8I. Hagen MC, Franzen O, McGlone F, Essick G, Dancer C, Pardo JV Tactile motion activates the human middle temporal/V5 (MT/V5) complex. Eur J Neurosci 2002, 16(5):957-964.

82. Ghazanfar AA, Maier JX, Hoffman KL, Logothetis NK: Multisensory integration of dynamic faces and voices in rhesus monkey auditory cortex. J Neurosci 2005, 25(20):5004-50I2.

83. Schroeder CE, Foxe JJ: The timing and laminar profile of converging inputs to multisensory areas of the macaque neocortex. Brain Res Cogn Brain Res 2002, I 4(I): 187-198.

84. Lakatos P, Chen CM, O'Connell MN, Mills A, Schroeder CE: Neuronal oscillations and multisensory interaction in primary auditory cortex. Neuron 2007, 53(2):279-292.

85. Ramos-Estebanez C, Merabet LB, Machii K, Fregni F, Thut G, Wagner TA, Romei V, Amedi A, Pascual-Leone A: Visual phosphene perception modulated by subthreshold crossmodal sensory stimulation. J Neurosci 2007, 27( 15):4I78-4I8I.

86. Romei V, Murray MM, Merabet LB, Thut G: Occipital transcrania magnetic stimulation has opposing effects on visual and auditory stimulus detection: implications for multisensory interactions. J Neurosci 2007, 27(43): | | 465- | |472.

87. Kayser C, Petkov Cl, Augath M, Logothetis NK: Functional imaging reveals visual modulation of specific fields in auditory cortex. J Neurosci 2007, 27(8): 1824-| 835 .

88. Lehmann C, Herdener M, Esposito F, Hubl D, di Salle F, Scheffler K, Bach DR, Federspiel A, Kretz R, Dierks T, et al.: Differential patterns of multisensory interactions in core and belt areas of human auditory cortex. Neuroimage 2006, 3 I (I):294-300.

89. Driver J, Noesselt T: Multisensory interplay reveals crossmoda influences on 'sensory-specific' brain regions, neural responses, and judgments. Neuron 2008, 57(I): I I-23.

90. Macaluso E: Multisensory processing in sensory-specific cortical areas. Neuroscientist 2006, I 2(4):327-338.

91. Stanford TR, Quessy S, Stein BE: Evaluating the operations underlying multisensory integration in the cat superior colliculus. J Neurosci 2005, 25(28):6499-6508.

92. Stein BE: Neural mechanisms for synthesizing sensory information and producing adaptive behaviors. Exp Brain Res 1998, I 23(I-2): I24-135

93. Meredith MA, Stein BE: Interactions among converging sensory inputs in the superior colliculus. Science 1983 , 221 (4608):389-39I.

94. Meredith MA, Stein BE: Spatial factors determine the activity of multisensory neurons in cat superior colliculus. Brain Res 1986, 365(2):350-354

95. Sugihara T, Diltz MD, Averbeck BB, Romanski LM: Integration of Auditory and Visual Communication Information in the Primate Ventrolateral Prefrontal Cortex. J Neurosci 2006, 26(43): I I I38- I I I47.

96. Romanski LM: Representation and integration of auditory and visual stimuli in the primate ventral lateral prefrontal cortex. Cereb Cortex 2007, I 7(Suppl I):i6I-69.

97. Bizley JK, Nodal FR, Bajo VM, Nelken I, King AJ: Physiological and anatomical evidence for multisensory interactions in auditory cortex. Cereb Cortex 2007, 17(9):2172-2189.

98. Woods TM, Lopez SE, Long JH, Rahman JE, Recanzone GH: Effects of stimulus azimuth and intensity on the single-neuron activity in the auditory cortex of the alert macaque monkey. J Neurophysiol 2006, 96(6):3323-3337.

99. Rowland BA, Quessy S, Stanford TR, Stein BE: Multisensory integration shortens physiological response latencies. J Neuros $C$ 2007, 27(22):5879-5884.

100. Sherman SM: The thalamus is more than just a relay. Curr Opin Neurobiol 2007, 17(4):417-422.

10I. Cappe C, Barone P, Rouiller E: Thalamo-cortical connectivity for multisensory and motor integration in monkeys. In Annual meeting of the Swiss Neuroscience Society: 2006 Bale, Switzerland; 2006.

102. Spence C, McDonald J, Driver J: Exogenous spatial-cuing studies of human crossmodal attention and multsensory integration. In Crossmodal space and crossmodal atention Edited by: Spence 
C, Driver J. Oxford New york: Oxford University Press; 2004:277-320.

103. Maunsell JH, Treue S: Feature-based attention in visual cortex. Trends Neurosci 2006, 29(6):317-322.

104. Reynolds JH, Chelazzi L: Attentional Modulation of Visual Processing. Annu Rev Neurosci 2004, 27:6I I-647.

105. Sary G, Koteles K, Chadaide Z, Tompa T, Benedek G: Task-related modulation in the monkey inferotemporal cortex. Brain Res 2006, I I 2 I (I):76-82.

106. Haenny PE, Schiller PH: State dependent activity in monkey visual cortex. I. Single cell activity in VI and V4 on visual tasks. Exp Brain Res 1988, 69(2):225-244.

107. McDonald JJ, Teder-Salejarvi WA, Ward LM: Multisensory integration and crossmodal attention effects in the human brain. Science 200I, 292(5523): I79I.

108. Fort A, Delpuech C, Pernier J, Giard MH: Dynamics of corticosubcortical cross-modal operations involved in audio-visual object detection in humans. Cereb Cortex 2002, I2(10): 1031-1039.

109. Bell AH, Corneil BD, Munoz DP, Meredith MA: Engagement of visual fixation suppresses sensory responsiveness and multisensory integration in the primate superior colliculus. Eur J Neurosci 2003, I8(1 0):2867-2873.

I I0. Nascimento-Silva S, Schroeder CE, Hackett TA, Ulbert I, Karmos G, Smiley JF: Projection from area V2 to auditory area Tpt in the superior temporal gyrus. Society for Neurosciences: Washington 2005:617.616

III. Rauschecker JP: Compensatory plasticity and sensory substitution in the cerebral cortex. Trends Neurosci 1995, I 8(I):36-43.

I I2. Bavelier D, Dye MW, Hauser PC: Do deaf individuals see better? Trends Cogn Sci 2006, I O( I I):5 I2-5I 8.

1 13. Bavelier D, Neville HJ: Cross-modal plasticity: where and how? Nat Rev Neurosci 2002, 3(6):443-452.

I 14. Sadato N, Pascual-Leone A, Grafman J, Ibanez V, Deiber MP, Dold G, Hallett M: Activation of the primary visual cortex by Braille reading in blind subjects. Nature 1996, 380(6574):526-528.

1 15. Wallace MT, Meredith MA, Stein BE: Multisensory integration in the superior colliculus of the alert cat. J Neurophysiol 1998, 80(2): $1006-1010$.

I 16. Wallace MT, Wilkinson LK, Stein BE: Representation and integration of multiple sensory inputs in primate superior colliculus. J Neurophysiol 1996, 76(2): 1 246- 1266.

117. Sparks DL: The brainstem control of saccadic eye movements. Nat Rev Neurosci 2002, 3( I 2):952-964.

I 18. Collins CE, Lyon DC, Kaas JH: Distribution across cortical areas of neurons projecting to the superior colliculus in new world monkeys. Anat Rec A Discov Mol Cell Evol Biol 2005, 285(I):619-627.

119. Ernst $\mathrm{MO}$, Bulthoff $\mathrm{HH}$ : Merging the senses into a robust percept. Trends Cogn Sci 2004, 8(4):162-169.

120. Fries P, Neuenschwander S, Engel AK, Goebel R, Singer W: Rapid feature selective neuronal synchronization through correlated latency shifting. Nat Neurosci 200I, 4(2): 194-200.

121. Felleman DJ, Van Essen DC: Distributed hierarchical processing in the primate cerebral cortex. Cereb Cortex I99I, I(I):I-47.

122. Barone $\mathrm{P}$, Batardiere A, Knoblauch $\mathrm{K}$, Kennedy $\mathrm{H}$ : Laminar distribution of neurons in extrastriate areas projecting to $\mathrm{VI}$ and V4 correlates with the hierarchical rank and indicates the operation of a distance rule. J Neurosci 2000, 20(9):3263-328I.

123. Rockland KS, Van Hoesen GW: Direct temporal-occipital feedback connections to striate cortex (VI) in the macaque monkey. Cereb Cortex 1994, 4(3):300-3।3.

124. Sousa AP, Pinon MC, Gattass R, Rosa MG: Topographic organization of cortical input to striate cortex in the Cebus monkey: a fluorescent tracer study. J Comp Neurol 1991, 308(4):665-682.

125. Morecraft RJ, Rockland KS, Van Hoesen GW: Localization of area prostriata and its projection to the cingulate motor cortex in the rhesus monkey. Cereb Cortex 2000, 10(2):192-203.

126. Roelfsema PR, Lamme VA, Spekreijse H: Object-based attention in the primary visual cortex of the macaque monkey. Nature 1998, 395(6700):376-38I.

127. Motter BC: Focal attention produces spatially selective processing in visual cortical areas VI, V2, and V4 in the presence of competing stimuli. J Neurophysiol 1993, 70(3):909-919.

128. Vidyasagar TR, Pigarev IN: Modulation of neuronal responses in macaque primary visual cortex in a memory task. Eur J Neurosci 2007, 25(8):2547-2557.
129. Super H, Spekreijse H, Lamme VA: A neural correlate of working memory in the monkey primary visual cortex. Science 200I, 293(5527): $120-124$.
Publish with Bio Med Central and every scientist can read your work free of charge

"BioMed Central will be the most significant development for disseminating the results of biomedical research in our lifetime. "

Sir Paul Nurse, Cancer Research UK

Your research papers will be:

- available free of charge to the entire biomedical community

- peer reviewed and published immediately upon acceptance

- cited in PubMed and archived on PubMed Central

- yours - you keep the copyright

Submit your manuscript here:

http://www.biomedcentral.com/info/publishing_adv.asp 